\title{
Provider diversity in the English NHS: a study of recent developments in four local health economies
}

Article

Accepted Version

Allen, P., Turner, S., Bartlett, W., Perotin, V., Matchaya, G. and Zamora, B. (2012) Provider diversity in the English NHS: a study of recent developments in four local health economies. Journal of Health Services Research \& Policy, 17 (suppl 1). pp. 23-30. ISSN 1758-1060 doi:

https://doi.org/10.1258/jhsrp.2011.011015 Available at https://centaur.reading.ac.uk/24489/

It is advisable to refer to the publisher's version if you intend to cite from the work. See Guidance on citing.

To link to this article DOI: http://dx.doi.org/10.1258/jhsrp.2011.011015

Publisher: Royal Society of Medicine Press

Publisher statement: Allen, P., Turner, S., Bartlett, W., Perotin, V., Matchaya, G. and Zamora, B. (2011) Provider diversity in the English NHS: a study of recent developments in four local health economies. Journal of Health Services Research \& Policy. pp. 1-8. ISSN 1758-1060 (In Press) DOI:

10.1258/jhsrp.2011.011015 This is the final draft, after peer-review, of a manuscript published in RSM journals: www.rsmpress.com

All outputs in CentAUR are protected by Intellectual Property Rights law, including copyright law. Copyright and IPR is retained by the creators or other copyright holders. Terms and conditions for use of this material are defined in 
the End User Agreement.

www.reading.ac.uk/centaur

\section{CentAUR}

Central Archive at the University of Reading

Reading's research outputs online 
Provider Diversity in the NHS: a study of recent developments in four health economies Pauline Allen, PhD (1) *; Simon Turner, PhD (2); Will Bartlett, PhD (3); Virginie Perotin, $\mathrm{PhD}$ (4); Greenwell Matchaya, $\mathrm{PhD}$ (5); Bernarda Zamora, PhD (6)

(1) London School of Hygiene and Tropical Medicine

(2) King's College London

(3) London School of Economics

(4) University of Leeds

(5) Reading University

(6) Bristol University

*Corresponding author

Department of Health Services Research and Policy

Faculty of Public Health and Policy

London School of Hygiene and Tropical Medicine

15-17 Keppel Street

London WC1H 9SH

pauline.allen@1shtm.ac.uk

Objectives: The overall objective of the research was to assess the impact of provider diversity on quality and innovation in the English NHS. The aims were to map the extent of diverse provider activity, identify the differences in performance between Third Sector Organisations (TSOs), for-profit private enterprises, and incumbent organisations within the NHS, and the factors that affect the entry and growth of new private and TSOs.

Methods: Case studies of four Local Health Economies (LHEs). Data included: semi-structured interviews with 48 managerial and clinical staff from NHS organizations and providers from the private and Third Sector; some documentary evidence; a focus group with service users; and routine data from the Care Quality Commission and Companies House. Data collection was mainly between November 2008 and November 2009.

Results: Involvement of diverse providers in the NHS is limited. Commissioners' local strategies influence degrees of diversity. Barriers to the entry for TSOs include lack of economies of scale in the bidding process. Private providers have greater concern to improve patient pathways and patient experience, whereas TSOs deliver quality improvements by using a more holistic approach and a greater degree of community involvement. Entry of new providers drives NHS Trusts to respond by making improvements. Information sharing diminishes as competition intensifies. 
Conclusions: There is scope to increase the participation of diverse providers in the NHS, but care must be taken not to damage public accountability, overall productivity, equity and NHS providers (especially acute hospitals, which are likely to remain in the NHS) in the process.

\section{$\underline{\text { Introduction }}$}

Over the last decade there has been a marked shift in government policy to introduce a wider diversity of providers available to NHS patients in England (but less so in other UK countries). (1) Reform of various aspects of the NHS is occurring simultaneously, and supply side changes are a key element in the overall package. (2) The New Labour government's view was that competition on the supply side would improve efficiency, quality of care and responsiveness to patients; and that new providers would be more innovative. Instead of most services being run by publicly owned bodies, there was an explicit decision to increase the diversity of types of providers offering services to NHS patients to include organisations from the independent sector. This policy is being continued by the recently elected coalition government. (3) Providers of healthcare to NHS patients can be independent: both in the form of for-profit and not for profit Third Sector Organisations (TSOs), the latter including social enterprises, (which in fact may be profit making) ${ }^{1}$.

Some concerns have been raised about the use of non NHS providers. (4) (5) (6) Increasing competition may not stimulate overall efficiency in the health care system. The economics of contracting (7) indicates that the transactions costs of contracting out healthcare will be significant. If these are taken into account, the supposed increased efficiency produced by competition is made more questionable. ${ }^{2}$ Difficulties in contracting for healthcare might allow providers with strong incentives to cut costs to reduce quality of care without commissioners being able to detect this or enforce improvements (13). Introducing a quasimarket for health care requires skilful commissioning in order to ensure services meet population needs. (6) Payment of public money to independent organisations raises concerns about diminution in public accountability, due to the more limited range of mechanisms by which accountability can be enforced outside the public sector (14).

For-profit independent sector treatment centres (ISTCs) were invited into the NHS with the aim of providing extra capacity needed to reduce waiting times for elective surgery. ISTCs would also increase choice for patients; introduce innovative models of service delivery; and stimulate efficiency through competition (2) (15). The Department of Health anticipated that ISTCs would contribute 15 per cent of NHS elective surgical procedures (2), but they contribute less than 2 per cent (16). There have been no published quantitative studies of the technical efficiency of ISTCs. A comparison of clinical quality found no significant differences between ISTCs and NHS providers (17). A study of patient experience (18)

\footnotetext{
${ }^{1}$ In fact, one can distinguish between a) organisations that can make a profit but are not allowed (or do not allow themselves in some permanent way) to distribute it to their "owners"; and b) those organisations that are allowed to distribute any profit they make to their owners. A social enterprise could be either.
}

2 There is an extensive literature giving detailed explanations of the effect of transactions cost economics on contracting for healthcare (e.g. 8, 9, 10, 11,12). 
found a number of variables were rated higher in ISTCs than NHS organisations. There were occasional difficulties in ensuring coordinated care where responsibility for care moved between ISTCs and NHS providers. For profit providers of general practice have also been invited into the NHS, but there are, as yet, no studies evaluating this development.

New providers from the social economy are encouraged to join the NHS (19). Third Sector organisations (TSOs) are independent of the state and have social aims (20). TSOs are meant to develop the entrepreneurial impulse within health and social care, encourage entry of new providers, improve quality, and promote innovation (21). Existing NHS community health services are being encouraged to transform themselves into social enterprises (21). There are no quantitative studies comparing the performance of TSOs providing health care to NHS patients with the performance of NHS providers. An evaluation of social enterprise 'pathfinders' in the NHS (22) () found it was too early in their development to tell how they were performing. In terms of international work, there is no evidence in the health care sector that TSOs are less efficient than for-profit organisations (23) (24) (25).

We have been able to add substantially to the small amount of evidence available about diverse providers in the NHS by studying the extent of diverse provider activity and its effects on NHS providers in four local health economies. The aims were to map the extent of diverse provider activity, attempt to identify the differences in performance between TSOs, for-profit private enterprises, and incumbent organisations within the NHS, and also the factors that affect the entry and growth of new private and TSOs.

$\underline{\text { Study design and methods }}$

The study used case studies of four Local Health Economies (LHEs). The LHEs were associated with four PCTS across England. (A quantitative study of patient experience comparing all ISTCs and NHS providers was also carried out. The detail of this is reported elsewhere (26). Case studies were selected as the most suitable research strategy. The range of issues investigated is wide, and the concepts were related to each other in complex ways (27). The choice of LHEs was made to reflect differences in relative levels of deprivation and demographic characteristics, including variation in the size of black and minority ethic (BME) communities, as increasing provider diversity is supposed to help address these needs. (See Appendix 1 for details of case study sites.) To facilitate the analysis, two tracers were used: elective orthopaedic surgery (replacement of hips and knees) and home health care for frail older people. The former afforded the best way to compare ISTCs and NHS providers, while it was hoped that the latter would be covered by all three types of providers, including the Third Sector.

Semi-structured interviews with 48 managerial and clinical staff from a variety of NHS organisations, including NHS Trusts, Foundation Trusts, and PCTs, as well as providers from the private and Third Sector were undertaken. One ISTC was included in the sample. The local PCT in each LHE was recruited first to the study. They provided information on providers within the two 'tracer' specialities. We then wrote to the CEO of each provider requesting their participation, and asking for names of relevant staff to interview. It was more difficult to recruit private and TSOs than NHS organisations to the study. Once recruited, proceeding with research at non-NHS organisations was easier due to less onerous procedures for gaining access. Some documentary evidence, such as their constitution and annual reports, an organogram, contracts, and routine performance and contract monitoring data were collected. A focus group was arranged in a TSO in LHE B to gauge service users' satisfaction with new forms of provider. This involved service users and volunteers related to two TSOs providing care services for older people. 
Despite strenuous efforts, it was not possible to arrange focus groups in the other LHEs. Finally, we used routine data, such as the Care Quality Commission (CQC) data, and data stored at Companies House, to map the types of provider in each LHE. Companies House has ownership data for different companies, which is what we needed in order to classify the enterprises in the four LHEs into private and public or voluntary sectors. Table 1 summarises the number and roles of staff interviewed and types of organization in each of the LHEs.

Table 1. Summary of data collected from LHEs.

\begin{tabular}{|c|c|c|c|c|}
\hline \multirow[t]{2}{*}{ Case study area } & \multicolumn{3}{|l|}{ Interviews } & \multirow[t]{2}{*}{ Additional data } \\
\hline & Public & For-profit & Third sector & \\
\hline LHE A & $\begin{array}{l}\text { PCT (commissioning } \\
\text { director); PCT provider } \\
\text { unit (managing } \\
\text { director, consultant } \\
\text { nurse); FT (CEO, } \\
\text { medical director, } \\
\text { clinical director); } \\
\text { Acute trust (CEO, } \\
\text { finance director, } \\
\text { clinical director); Local } \\
\text { authority (service } \\
\text { manager for home } \\
\text { care) }\end{array}$ & $\begin{array}{l}\text { ISTC (chairman); } \\
\text { Home healthcare } \\
\text { (managing director) }\end{array}$ & $\begin{array}{l}\text { GP cooperative } \\
\text { (operational } \\
\text { director) }\end{array}$ & \\
\hline LHE B & $\begin{array}{l}\text { PCT (commissioning } \\
\text { director); PCT provider } \\
\text { unit (managing } \\
\text { director); FT (strategy } \\
\text { director); } \\
\text { Orthopaedics specialty } \\
\text { trust (CEO, } \\
\text { commissioning } \\
\text { director) }\end{array}$ & & $\begin{array}{l}\text { Local charity for } \\
\text { older people } \\
\text { (managing director); } \\
\text { National charity for } \\
\text { older people } \\
\text { (managing director); } \\
\text { Charity providing } \\
\text { home care (service } \\
\text { manager). }\end{array}$ & $\begin{array}{l}\text { Focus group with two } \\
\text { TSOs providing care } \\
\text { services for older } \\
\text { people, involved } \\
\text { volunteers and } \\
\text { service users }\end{array}$ \\
\hline LHE C & $\begin{array}{l}\text { PCT (associate } \\
\text { commissioning } \\
\text { directors); FT (CEO); } \\
\text { PCT provider unit } \\
\text { (interim managing } \\
\text { director, service } \\
\text { director) }\end{array}$ & $\begin{array}{l}\text { Diagnostic service } \\
\text { (chief operating } \\
\text { officer, medical } \\
\text { director); Primary } \\
\text { care provider } \\
\text { (medical director); } \\
\text { Acute and } \\
\text { community care } \\
\text { provider (managing }\end{array}$ & $\begin{array}{l}\text { Integrated health } \\
\text { centre (GP); } \\
\text { National charity for } \\
\text { dementia (various } \\
\text { frontline staff); } \\
\text { Social enterprise } \\
\text { primary care } \\
\text { consortium } \\
\text { (director). }\end{array}$ & \\
\hline
\end{tabular}




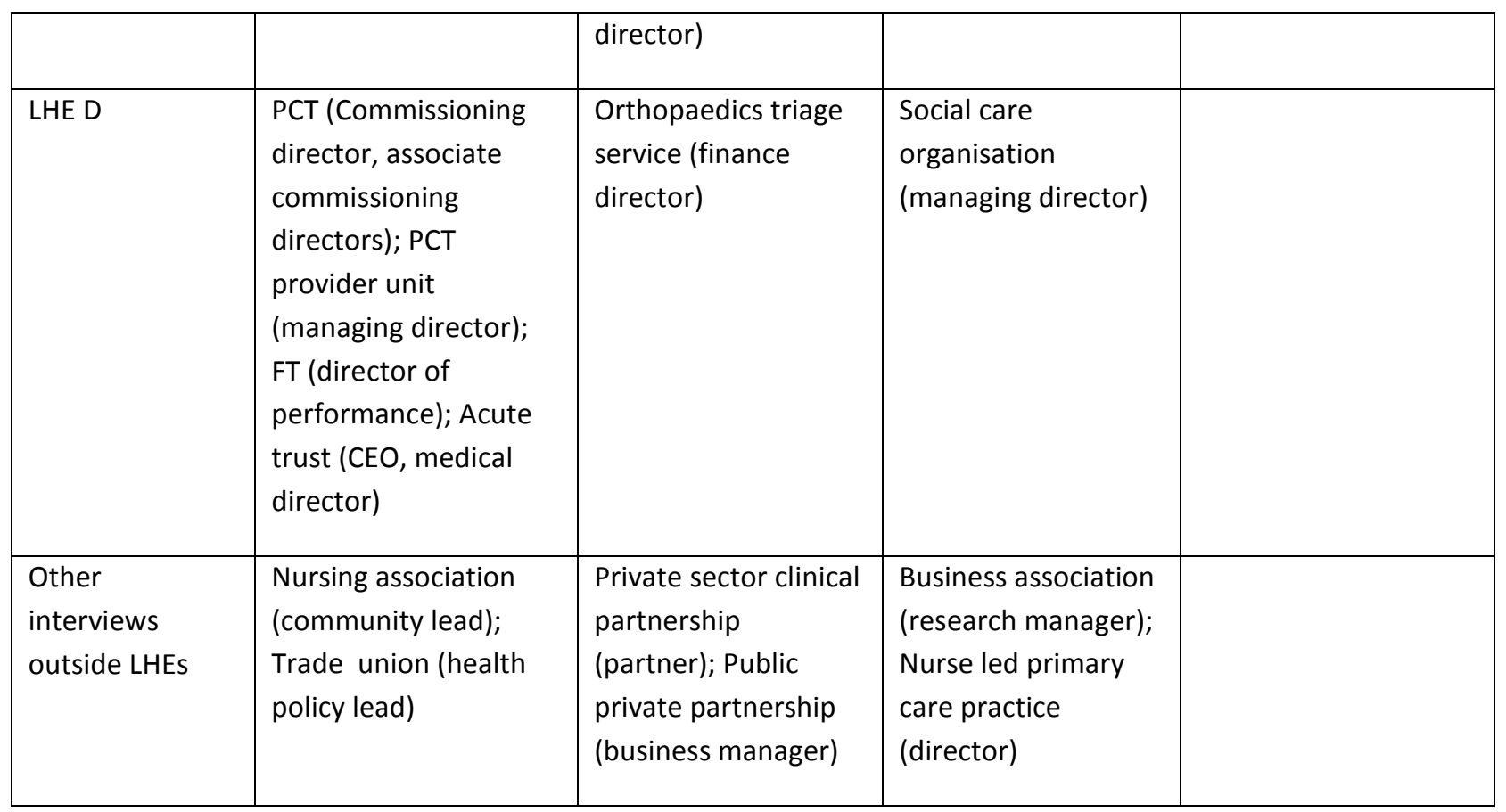

The majority of the interviews were conducted between November 2008 and November 2009.

The research questions for the study were used to generate an initial set of categories, which were used to code the data from the interviews. An iterative process was used, under which the categories are applied to the data, and amendments made in accordance with what the data revealed (28). A similar process was used to analyse the documents (other than purely financial documents).

\section{$\underline{\text { Results }}$}

\section{Mapping extent of diverse provision}

The PCT commissioning teams within each LHE were to supply details of providers from the NHS, private sector, and Third Sectors with whom they were contracting. These were of variable detail. All indicated that a very limited proportion of contracts by value go to diverse providers. In LHE D, $2.6 \%$ of funding went to private companies and $0.6 \%$ to TSOs.

There was greater involvement of diverse providers in orthopaedic surgery than the provision of home health care for older people. Two of the LHEs sent some orthopaedic patients to local ISTCs. There are no orthopaedic ISTCs in London, but the LHEs there did use a city-wide for-profit diagnostic service. Community health services were dominated by the provider units of PCTs, some of which-were being spun-off into arm's length entities, although none had registered an intention to become a social enterprise under the national 'Right to Request' scheme. In community health services, many of the relationships with non-NHS organisations were commissioned jointly with the local authority, reflecting the work of these providers at the interface of social and health care.

Total numbers of potential providers of home healthcare in addition to those actually providing it to NHS patients were found in the CQC database. All four LHEs had few non-NHS health care providers, 
although voluntary sector participation was increasing. For-profits had higher entry rates than TSOs. There were more diverse providers available than those currently contracted to the NHS, suggesting a potential for further development.

\section{Entry and growth of diverse providers}

Diverse providers were welcomed by commissioners because they were perceived to possess distinct characteristics. In relation to TSOs, the commissioning director at PCT B said they were used because they either possessed 'niche expertise' in specific areas of healthcare or because they had access to parts of the population not covered by the PCT. Commissioners' views on for-profit providers varied. In PCT A, the commissioner interviewed considered that the local ISTC had demonstrated efficiency advantages over the NHS by introducing 'leaner pathways' for patients and modern booking systems. In PCTs B and C commissioners noted the superior performance of ISTCs, such as a 'better hotel service' for patients (PCT C), but they also recognised that it was problematic to compare NHS organisations with the private sector because the latter tended to 'cherry pick' more profitable streams of work and operate with a lower cost base.

The PCTs varied in their approach towards the commissioning of diverse providers. Contract tendering at PCT A was the default position, whereas elsewhere it was not, and decisions were made on a case by case basis. Competition for NHS provision was perceived by the commissioners at PCT A to be delivering two main benefits. The process of tendering for contracts was stimulating providers to come up with more 'innovative' and higher quality responses. Plurality of providers encouraged providers to focus on their performance, including innovation and quality. The other PCTs had not embraced market competition to this same extent. The commissioning director at PCT B stated that its approach was driven by 'getting value for money for everything we commission' and his view was that, in many cases, tendering for contracts is not the best way of achieving this, given the significant costs of running a tendering process. Instead, he believed that commissioners should concentrate on evaluating the performance of existing services, and not contracting out the service if incumbents were performing adequately.

Respondents from diverse providers holding NHS contracts highlighted two barriers to gaining PCT contracts. The first is that time and capital investment required to respond to a tender process is prohibitive. Secondly, smaller providers do not possess the economies of scale enjoyed by larger organisations, reducing their price competitiveness. Commissioners recognise additional barriers. The commissioning director at PCT B pointed out that new organisations could be at a disadvantage because the procurement process would identify the absence of a track record as a 'big risk', and 'we're all very risk averse in the NHS'. The commissioning director at PCT A anticipated less involvement of private sector organizations and TSOs in the delivery of acute care, as opposed to the community, because of the high costs of market entry.

Commissioners also saw that part of their role was to develop a level playing field for providers tendering for contracts. The commissioning director from PCT B recognised that TSOs had limited ability to respond to NHS tenders. This meant the PCT should not be 'too much more commercial' in how they commissioned services, in order not to disadvantage smaller TSOs. PCT A organised workshops for potential providers from different sectors geared towards responding effectively to NHS tenders. 
Once contracts were awarded, several further issues were highlighted. Several providers, both new and incumbent, stated that the competitive tendering system discourages the sharing and piloting of new ideas, out of concern that the PCT would pirate promising service developments and translate them into a tender for a new contract to be openly contested. (This concern was also raised by NHS incumbent providers.) A director of a GP cooperative in PCT A stated that there had been instances of resistance to his organisation from incumbent providers, particularly when providing new services that involved acute care. Socio-economic characteristics of the area may influence growth of new providers. In LHE C, which covers one of the most deprived local authorities in England, a large public company that had recently been awarded a ten-year contract to run a primary care practice told us that it had encountered problems with very high consultation rates, compared to the national average.

\section{Performance of each type of provider}

The case study research demonstrated that the issues in respect of performance varied between types of provider, so we report these in turn.

\section{For-profit providers:}

For-profit providers deliver services in a whole range of acute, primary and community health services in the case study areas. There is diversity in the structure of their internal governance arrangements. The ISTC in LHE A is based on a hierarchical governance structure in which the decision-making of executive directors take precedence over the views of the clinicians delivering frontline care. As a new organisation independent of the historical social relations within the NHS, the creation of this enterprise has provided an opportunity to reconfigure the relations between management and clinicians. This has allowed the ISTC's managers to focus on the organisational systems and processes they deem necessary to treat patients efficiently, and to recruit surgeons capable of engaging with a predefined system of providing care. Another for-profit provider has an alternative governance structure based on employee co-ownership. This provider runs a chain of ISTCs as well as purpose-built hospitals, clinics, and community services. On joining the company, members of staff receive a shareholding and have a combined ownership stake of $49.9 \%$. (The remainder of the company is owned by institutional investors who provide investment capital to the organisation.) The purpose of providing staff with a stake in the business is to create an environment in which staff are encouraged to take ownership of the way services are delivered. This latter approach to organizational structure (as opposed to the hierarchical one) may reflect the origin of the company (it was founded by former NHS surgeons; ) and that it wishes to incentivise clinicians to attract non NHS patients too.

While the study did not investigate the relative efficiency of each type of provider (as data were not available for for-profit providers), interviews with staff in LHE A identified a number of characteristics of ISTCs that might contribute to greater efficiency. ISTCs are committed to technical efficiency as a means for generating a profit. The focus on efficiency is aided by the limited range of services that many provide (mainly elective procedures or diagnostic services), allowing them to focus on the most productive means for delivering clear pathways of care. In the ISTC near LHE A, the average length of stay for total joint replacements was reported to compare favourably with that in the NHS. The organisation's chairman indicated that their service delivery model uses a carefully constructed patient pathway. This begins with clear admission criteria that exclude patients with 'unstable co-morbidities'. Once accepted for treatment, patients are educated about the treatment process. This allows the centre to operate a shorter length of 
stay. This ISTC's performance is driven by a competitive motive, encouraging both efficiency and a 'the need to be seen to be better than anything that is provided in the public sector in terms of outcomes and quality'. This has been achieved by designing a technical system in which the clinician participates in the production process but has little influence on how the centre is run.

Private sector providers tend to use patient or 'consumer' feedback to ensure the provision of high quality services, whether as a tool for managing staff performance or as a perspective around which to design services. A key characteristic of private sector providers is their attentiveness to the patient, often cast as a knowledgeable 'consumer'. The chairman of the ISTC in LHE A said it aims to 'continually refine the patient experience' in order to achieve a competitive advantage over NHS providers.

Data on patient experience in ISTCs and comparable NHS facilities is reported in detail elsewhere. (26) To summarise, the NHS Trust inpatient surveys (2007) and the ISTC inpatient and day case patient surveys (2007 and 2008) were analysed and we found that ISTCs seemed to provide better all-round quality, fewer delays in discharge and more comfort than NHS hospitals, while NHS hospitals were rated better on information given to patients. However, these differences were entirely due to differences in the types of cases admitted into the ISTCs and NHS hospitals and the selection of patients into one or the other sector. A more nuanced picture was produced by the detail of the multivariate analysis which found that older patients and patients in particular specialties were more satisfied with care in NHS hospitals, and patients in some other specialties with care in ISTCs, all else being equal. Overall, regression analysis found no differences in the level of satisfaction reported by patients on the basis of ownership per se once patient characteristics, state of health and length of stay, hospital specialty, the selection process of patients into either sector and individual hospitals' characteristics were taken into account. The analysis was unable to identify which features of providers accounted for differences in patient experience, but suggestions included qualifications of staff, resources and equipment.

Being aware of patient needs was seen as a source of innovation. A national private sector provider of home care, contracting with PCT A, designs its services from the patient's perspective. It delivers pharmacy and healthcare services (including blood transfusions and chemotherapy) in people's homes that would otherwise be administered in healthcare settings. It employs over 750 staff and delivers services to 100,000 patients per year. Private sector organisations are not markedly technically innovative in comparison to the NHS, however. The differences lie in their ability to implement change, whether in the form of innovation or in the form of a restructuring of pre-existing services. The high level of specialisation of some for-profit organisations means that, when making decisions, they do not have to deal with the same wide breadth of stakeholders and competing demands on resources as an NHS trust.

In the field of community health services, many of the smaller (locally based) private sector providers do not provide more innovative or effective care than traditional NHS providers. Many have traditionally provided social and other non-clinical forms of care to their users, with the provision of 'health' care being a relatively new domain which they often learn initially from the NHS.

\section{Third Sector Providers}

The Third Sector includes a diverse range of enterprises with different models of ownership and organisation. Providers from this sector deliver services in primary and community health services, but 
none currently provide acute care. As there are no routine data available concerning TSOs in community or primary care, the performance of TSOs could be compared using quantitative methods.

The case study research indicated that TSOs do not necessarily provide more innovative or effective care than traditional NHS providers. A lack of resources was found in some cases to be a problem. One primary care practice was set up as a social enterprise led by nurses, rather than the traditional GP. The nurses had decided to bid to run the practice due to their concern that private companies with a different ethos of care might be awarded the contract. The practice is run from cramped premises and, notwithstanding a longstanding desire to move to a larger purpose-built primary care centre, the practice generates little surplus revenue to invest in improving the fabric of the building and providing innovative new services. However, they are able to offer modest additional services to patients (e.g. foot clinics).

Some TSOs successfully engage with the needs of the communities that they serve. This is accomplished through bringing healthcare services into community spaces and transcending the boundary between healthcare and other forms of community activity. A local branch of a national charity for older people based in LHE B is funded by the PCT to serve sufferers of dementia. It is able to identify and interact with service users outside traditional NHS settings. The organisation's ability to work in the community stems from its use of local volunteers and its links with neighborhood groups that provide access to hardto-reach individuals within the community. An innovative GP health centre, a TSO based in LHE C, bridges the boundary between healthcare and other activities. The GP practice is situated physically within a broader community organisation that promotes the overall health and wellbeing of local people, integrating health care with the learning of new skills and the identification of employment and enterprise opportunities.

The relative independence of TSOs from statutory bodies makes some of these organisations more approachable for service users. The local office of a national dementia charity based in LHE C is supported by the PCT to employ two support workers, one supporting sufferers of dementia under the age of 65, and the other dedicated to helping sufferers from the largest minority ethnic group in the LHE. This was also an example of an innovative service, filling a gap in statutory services.

TSOs are oriented towards the interests of their staff or other stakeholders, such as service users. The research identified both types of organisations. Serving the interests of staff creates an organisation which adheres to a particular set of values. For example, a consortium of GPs and other primary care workers had formed a society for the benefit of the community through which GP practices collaborate in order to improve the quality of practice-based commissioning. It is governed by a Council that is elected from the membership of participating primary care staff and members of the public (the membership includes 60 to 70 people from the local community). Forming a new mutual organisation enabled the incumbent primary care practices to build a competitive advantage against new entrants. It also provided a vehicle to express a particular ethos that distinguishes this organisation from the values of the private for-profit sector.

Other TSOs seek to represent patients as stakeholders. A local charity contracting with PCT B that provides over 160 activities per week for older people is run by trustees elected from the organisation's membership body. The management committee consists of nine older people elected by the organisation's users, who then co-opt six additional directors. This structure has created an organisation that is led by the needs of its users. The TSOs interviewed also relied to a varying extent on the contributions of local 
volunteers. For example, two charities for older people situated in LHE B use volunteers to help provide services free-of-charge or at a reduced cost to users. One uses over 200 volunteers to provide a range of practical services including befriending, escorts to hospital appointments, staffing information and advice lines, and participating in intergenerational learning and skills transfer projects. Many of the volunteers are themselves older people and our focus group revealed the value that they derived from assisting others through volunteering.

\section{Effects of provider diversity on NHS providers}

In respect of orthopaedics, there is a difference in the breadth of services undertaken by incumbent NHS providers and the narrower specialised services offered by private sector organisations. NHS hospitals and private providers deliver services in only partially overlapping areas. The Foundation Trust in LHE A does not carry out a high volume of elective orthopaedic procedures, unlike the local ISTC. The orthopaedics done by the NHS includes more complex trauma work that involves specialist consultant input. Competition between different types of provider is partial - ISTCs (as envisaged by policy makers) only compete with NHS hospitals in respect of routine, non-urgent surgery. Moreover, there was some evidence that the entry of ISTCs might financially destabilise NHS providers. Several of the latter expressed concern that diverting more profitable, routine work to ISTCs would leave NHS organisations with a greater share of essential, complex and emergency care, which they cross-subsidise from the routine work they are undertaking.

ISTCs have a further effect on NHS providers: managers in LHE A noted that the presence of a local ISTC encourages them to 'raise their game'. They seek to mimic the more efficient operating practices of ISTCs (discussed above).

Community health services are an area of NHS care that many of the interviewees from the NHS recognised as having potential for improvement. The provision of community health services was undergoing change as provider units that were situated within PCTs were being separated from the commissioning function. One of the provider arms that we spoke to was involved in the Department of Health's Community Foundation Trust (CFT) pilot programme. The transition towards becoming a CFT, which involves setting up an independent provider board and separate financial accounts, had made the organisation more attuned to the needs of the community they were serving.

All the PCTs community services provider arms in the study had been through a period of restructuring. Greater attention is being paid to the strategic management. Elements of a market culture are emerging in the field of community health services as providers aim to build up their own repertoire of marketable skills and know-how, as a source of competitive advantage against potential rivals. Each community services organisation has focused on driving up productivity. PCT C reported that they have achieved a significant gain in productivity within district nursing, with further gains anticipated as an audit had revealed opportunities to adjust the skill mix, based on lower-banded staff undertaking many everyday nursing activities.

\section{$\underline{\text { Discussion and conclusion }}$}


The strengths of the study are its in-depth investigation of four LHEs over a period of some years. The weaknesses are that only four LHEs could be studied in such detail. This qualitative approach was necessary as there were so little routine quantitative data available about diverse providers.

We found that the extent of involvement of diverse providers in supplying services to the NHS is extremely limited. Commissioners' varying strategies strongly influence the degree of diversity in each case study area. Also, there are barriers to the entry of new organisations, especially TSOs, due to economies of scale in the bidding process. The growth of private sector providers is inhibited in deprived areas by greater demands of patients. There are differences in the way quality is delivered among the diverse providers. There is greater concern among private sector providers for improved organisation of patient pathways and for improved patient experience, whereas TSOs deliver quality improvements by using a more holistic approach and a greater degree of community involvement. There are significant process innovations in ISTCs concerning organisational and working practices. TSOs innovate by extending health care services throughout a broad range of community activities. Entry of new providers drives NHS Trusts to respond by introducing new surgical pathways, and place a greater emphasis on improving the patient experience. However, information sharing among incumbents diminishes as competition intensifies.

Our findings allow us to address concerns about the use of non-NHS providers. Some of the concerns have been reflected in the study. There are substantial transactions costs associated with contracting with new providers, which may indeed vitiate efficiency gains of competition. There is also concern voiced by the NHS about the financial damage to NHS trusts which contracting with ISTCs for routine work could inflict. Due to the fact that no routine cost data are available about for-profit providers of acute care, it is not possible to ascertain if services are economically either efficient, or of lower cost. This lack of information means that there is a diminution in the accountability for the use of public resources. However, data on patient experience in acute settings does not indicate that for-profit providers are delivering lower quality care. The lack of routine data on quality of care in community services and primary care make it impossible to compare diverse providers with the NHS.

The finding concerning the importance of commissioners' attitudes is particularly relevant in the light of current policy developments. As Coalition policy remains favorable to diverse providers (2), the stimulation of the entry of new social enterprises (29) and other providers will clearly require a strategic approach by commissioners. These will be transformed into GP consortia by April 2013. Under these new arrangements there will be less central control of the NHS, so new approaches and a degree of coordination may be needed to persuade GP commissioners to contract with diverse providers to provide NHS services, and to ensure they respond adequately to patient needs. However, the education and support of the new consortia and the commissioning of a broader range of providers are inevitably costly. In the current atmosphere of financial stringency, this may not be considered to be affordable.

\section{$\underline{\text { References }}$}

1. Edwards, N. and Lewis, R. (2008) 'Who owns and operates healthcare providers and does it matter?' Journal of the Royal Society of Medicine 101(2): 54-58

2. Department of Health (2005) Health reform in England: update and next steps. London: Department of Health.

3. Department of Health (2010) Equity and Excellence: liberating the NHS London: SO 
4. House of Commons Health Select Committee (2006) Independent Sector Treatment Centres. Fourth Report of Session 2005-06. London: The Stationary Office.

5. Pollock, A and Godden, S. (2008) 'Independent Sector Treatment Centres: evidence so far' British Medical Journal 335: 421-424

6. Allen, P. (2009) 'Restructuring the NHS again: supply side reform in recent English health care policy' Financial Accountability and Management, 25(4): 343-389

7. Williamson, O. (1985), The Economic Institutions of Capitalism (Free Press, New York)

8. Roberts, J. (1993), 'Managing Markets' Journal of Public Health Medicine 15,4: 305-3

9. Ashton, T. (1997) 'Contracting for health services in New Zealand: a transaction cost analysis' Social Science and Medicine 46(3); 357367

10. Croxson, B. (1999), Organisational Costs in the New NHS: an introduction to the transaction costs and internal costs of delivering health care Office Of Health Economics: London

11. Allen, P. (2002), A socio-legal analysis of contracting in the NHS internal market using a case study of contracting for district nursing, Social Sciences and Medicine, 54: 255-66

12. Petsoulas, C., Allen, P., Hughes, D., Vincent-Jones, P. and Roberts, J. 'Contracts in England's new NHS market: continuity and change' under review

13. Preker, A. A. Harding. P. Travis (2000), 'Make or buy decisions in the production of healthcare goods and services: new insights from institutional economics and organisational theory' Bulletin of the WHO 78 (6) 779-790

14. Vincent-Jones, P. (2006) The new public contracting: regulation, responsiveness, relationality Oxford University Press, Oxford

15. Anderson, K. (2006). Independent Sector Treatment Centres: A report from Ken Anderson, Commercial Director, Department of Health, to the Secretary of State for Health. London: Department of Health.

16. Healthcare Commission and Audit Commission (2008) Is the treatment working? Progress with NHS system reform programme. London: Healthcare Commission.

17. Browne, J., Jamieson, L., Lewsey, J., Van der Meulen, J., Copley, L. and Black, N. (2008) 'Case-mix and patients' reports of outcome in Independent Sector Treatment Centres: Comparison with NHS providers', BMC Health Services Research, 78: 1-7.

18. Healthcare Commission (2007) Independent Sector Treatment Centres. London: Healthcare Commission.

19. Department of Health (2006) Our health, our care, our say: a new direction for community services, White Paper, Norwich: TSO

20. Allen, P., Bartlett, W., Perotin, V., Zamora, B. and Turner, S. (2011) 'New forms of provider in the English National Health Service' Annals of Public and Cooperative Economics 82:1 77-95

21. Department of Health (2006) Our health, our care, our say: a new direction for community services, White Paper, Norwich: TSO

22. Tribal (2010) Social Enterprises Pathfinder Evaluation Final Report London, Department of Health

23. Vining \& Globerman, (1999) 'Contracting-out health care services: a conceptual framework' Health Policy 46 77-96

24. Sloan, F., Picone, G., Taylor, D., and Chou, S. ( 2001) "Hospital ownership and cost and quality of care: Is there a dime's worth of difference?" Journal of Health Economics, 20, 1-21.

25. Eggleston, K., Shen, Y., Lau, J., Schmid, C and Chan, J. (2008) "Hospital Ownership and Quality of Care: What Explains the Different Results in the Literature?" Health Economics. 17 (12). 1345-62

26. Perotin, V., Zamora, B., Reeves, R., Bartlett, W., Allen, P. (2010) Does hospital ownership affect patient experience? An investigation into public-private sector differences in England (under review)

27. George, A, and Bennett, A. (2005) Case studies and theory development in the social sciences MIT Press, Cambridge MA

28. Miles, M. (1979) 'Qualitative data as an attractive nuisance- the problem of analysis.' Administrative Science Quarterly 24(4): 590-594

29. Maude, F. (2010) 'Francis Maude launches pathfinder mutuals' Cabinet Office Press Release 12 August http://www.cabinetoffice.gov.uk/newsroom/news_releases/2010/100812-pathfinder-mutuals.aspx 